\title{
Desenvolvendo a competência informacional: a experiência do curso de Biblioteconomia da UFPA com egressos do sistema penal e familiares atendidos pela Fábrica Esperança
}

Rubens da Silva Ferreira

Maria Raimunda Sampaio

\author{
Doutorando em Ciência da Informação (PPGCI- \\ IBICT/UFRJ). Mestre em Planejamento do \\ Desenvolvimento Regional (NAEA/UFPA).Docente \\ da Faculdade de Biblioteconomia \\ (FABIB/ICSA/UFPA) .Bacharel em \\ Biblioteconomia (UFPA)
}

Doutoranda em Gestão Empresarial (UAA).Mestre em Ciência da Informação (IBICT/UFRJ). Docente da Faculdade de Biblioteconomia (FABIB/ICSA/UFPA).Bacharel em Biblioteconomia (UFPA)

Maria de Nazaré dos Santos Corrêa

Especialista em Administração de Bibliotecas (UFPA).Docente da Faculdade de Biblioteconomia (FABIB/ICSA/UFPA).Bacharel Biblioteconomia (UFPA)

em

Armando Onofre da Silva Costa

Especialista em Administração Estratégica (UFPA) Técnico-administrativo (FABIB/ICSA/UFPA)

O presente trabalho faz um registro da experiência extensionista, no contexto da Faculdade de Biblioteconomia do Instituto de Ciências Sociais Aplicadas da Universidade Federal do Pará. Trata-se do projeto "Construindo a competência informacional através de estratégias de fortalecimento do uso educativo das Tecnologias de Informação e Comunicação", que, entre os meses de agosto e dezembro de 2011, concentrou as ações entre os egressos do sistema penal e familiares atendidos pela Fábrica Esperança. Partindo da pesquisaação, os sujeitos em foco foram envolvidos em atividades orientadas para o desenvolvimento das competências informacionais, em uma carga horária total de $160 \mathrm{~h}$. Entre docentes, discentes e pessoal técnico, a experiência 
permitiu refletir sobre o conceito de competência informacional, o qual se coloca como fundamental para se pensar a inclusão e a cidadania na sociedade da informação.

Palavras-chave: Extensão universitária; Competência informacional; Sociedade da informação.

\section{Developing the information literacy: the experience of the Library Science course of UFPA with people from the criminal system and relatives attended by the Fábrica Esperança}

The present work makes a register of the extensionist experience in the context of the Faculdade de Biblioteconomia of the Instituto de Ciências Sociais Aplicadas of the Universidade Federal do Pará. This is the project "Building the information literacy through of the strategies of consolidating of the educative use of the Technologies of Information", that among the months of August to December of 2011 concentrated the actions between the people from of the criminal system and relatives attended by the Fábrica Esperança. From the research-action, the subjects in focus were involved in oriented activities to the development of the information literacy in a total hourly load of 160 hours. Among professors, universitarians and technicians, the experience allowed to reflect about the concept of the information literacy, which is basic to think the inclusion and citizenship in the information society.

Keywords: University extension; Information literacy; Information society.

Recebido em 28.04.2013 Aceito em 18.06.2013 
Desenvolvendo a competência informacional: a experiência do curso de Biblioteconomia da UFPA com egressos do sistema penal e familiares atendidos pela Fábrica Esperança
Rubens da Silva Ferreira; Maria Raimunda Sampaio; Maria de Nazaré dos Santos Corrêa; Armando Onofre da Silva Costa

\section{Introdução}

Desde a consolidação da profissão de bibliotecário no século $X X^{1}$, muitas têm sido as mudanças experimentadas no âmbito do ensino de graduação no Brasil e no exterior, a fim de que as necessidades humanas de informações sejam atendidas de maneira rápida e precisa. Nessa direção, o movimento contínuo de revisão e de atualização curricular, pelo qual passam as universidades que possuem cursos de Biblioteconomia, evidencia que novas dinâmicas culturais, políticas, econômicas, tecnológicas, jurídicas, sociais e científicas se impõem aos chamados profissionais da informação, entre os quais figura o bibliotecário. Em parte, essas mudanças são impulsionadas pelas expectativas do mercado de trabalho, precisamente no que se refere às competências técnicas, comunicacionais e gerenciais desejáveis nesses profissionais, em tempos de capitalismo cognitivo (MIRANDA, 2004; COCCO, 2010). Isto se reflete, entre outros aspectos, no papel das universidades não apenas no ensino e na pesquisa, mas, também, na vivência do saber que se constrói dentro de seus muros, em articulação com uma realidade, por vezes, adversa, o que é oportunizado por meio de ações extensionistas. Por outro lado, temse o compromisso cidadão e o fazer ético, ambos indissociáveis do processo de formação, indicando as responsabilidades sociais que devem sustentar a prática profissional daqueles que escolheram a Biblioteconomia como um ofício para toda a vida, pautando-se pelos ideais de liberdade e de dignidade à pessoa humana, expressos no juramento profissional criado e defendido pelo bibliotecário, jornalista e poeta recifense Bastos Tigre (1882-1957).

É em face de uma realidade marcada por atualizações curriculares e novas demandas sociais que este paper tem por finalidade registrar e refletir sobre a experiência do projeto de extensão "Construindo a competência informacional através de estratégias de fortalecimento do uso educativo das Tecnologias de Informação". Esta ação extensionista foi desenvolvida no período de $1^{\circ}$ de agosto de 2011 a 30 de julho de 2012, por pessoal docente e técnico, bem como por discentes da Faculdade de Biblioteconomia (FABIB) do Instituto de Ciências Sociais Aplicadas (ICSA) da Universidade Federal do Pará (UFPA). Embora tal projeto tenha se desdobrado em duas frentes de trabalho, isto é, uma na biblioteca da E.E.E.F.M. "Deodoro de Mendonça" e outra no Infocentro do NavegaPará ${ }^{2}$ instalado na Fábrica Esperança, a socialização que se faz desta experiência está focada neste último. Tal escolha se dá, sobretudo, em razão do público-alvo atendido e das atividades desenvolvidas entre agosto e dezembro de 2011, aspectos esses que se revelaram

\footnotetext{
${ }^{1}$ Embora na história - precisamente na Antiguidade e no período medieval - possam ser encontradas aquilo que identificamos como práticas bibliotecárias pro forma, foi a institucionalização do curso de formação profissional pela École des Chartes, em 1821, que deu impulso à criação de outros do gênero, a exemplo do que fez a Columbia University, em 1889, com a sua School of Library Economy .

2 Programa iniciado na gestão (2007-2011) da então governadora Ana Júlia Carepa (PT) e que se mantém na gestão (2011- ) do atual governador Simão Jatene (PSDB). O NavegaPará tem como objetivo promover a inclusão social e digital na sociedade paraense, por meio do acesso gratuito à Internet.
} 
Desenvolvendo a competência informacional: a experiência do curso de Biblioteconomia da UFPA com egressos do

sistema penal e familiares atendidos pela Fábrica Esperança
Rubens da Silva Ferreira; Maria Raimunda Sampaio; Maria de Nazaré dos Santos Corrêa; Armando Onofre da Silva Costa

desafiadores aos docentes, discentes e pessoal técnico ${ }^{3}$ participantes do projeto, preparados mais para atuar no ambiente das bibliotecas do que em um espaço de ressocialização de indivíduos sentenciados pela justiça, que cumpriram ou que estavam a cumprir pena.

No cerne do projeto em foco, o que estava em questão não era somente a resposta a uma exigência pedagógica do curso de Biblioteconomia, em conformidade com as diretivas do Ministério da Educação (MEC). Mas, para além de uma obrigação institucional, a ação extensionista representou uma oportunidade para docentes, discentes e pessoal técnico se aproximarem do papel social do bibliotecário no que diz respeito à garantia do acesso à informação, o que se deu por meio do entendimento do conceito de competência informacional, trabalhado na interação com egressos do sistema penal e familiares atendidos pela Fábrica Esperança, em Belém (PA). Desse modo, sobretudo para docentes e discentes, foi instigante pensar e agir em direção ao desenvolvimento dessas competências junto a um segmento social menos favorecido quanto ao uso das Tecnologias de Informação e Comunicação (TIC), tal como será tratado a seguir.

\section{Na sala de aula: o espaço da literatura especializada e dos conceitos}

Inserida no esquema classificatório do Conselho Nacional de Desenvolvimento Científico e Tecnológico (CNPq) na grande área das Ciências Sociais Aplicadas e, respectivamente, na Área da Ciência da Informação, a Biblioteconomia, desde os anos de 1960, iniciou o deslocado do paradigma do documento para o da informação, o que se consolidou na década de 1990 . Nessa perspectiva, as atividades de ensino são orientadas tanto por um conjunto de disciplinas técnicas, que lhe dá especificidade e identidade, quanto por outras, orientadas para as questões profissionais e sociais da contemporaneidade, as quais sustentam uma formação mais global e humanista. Seja como for, essas linhas sob as quais o desenho curricular do curso de Biblioteconomia é urdido se fundem no conceito de informação, que, para autores da ordem de Belking e de Robertson (1976), constitui-se no elemento modificador das estruturas cognitivas do homem. É, pois, a partir desse conceito central para a Ciência da Informação e para a Biblioteconomia que toda uma literatura especializada passa a ser produzida para dar conta dos processos sociais de geração, seleção, análise, representação, armazenamento, recuperação, disseminação e uso de informações.

Embora desde os primórdios da humanidade a informação seja encontrada em diferentes sociedades, com níveis de desenvolvimento tecnológico também distintos, a elevação ao status de fenômeno é produto da passagem da sociedade industrial para a pós-industrial. Nessa passagem foi decisiva não apenas a crise no regime fordista de

\footnotetext{
${ }^{3}$ Isso porque o servidor técnico-administrativo que colaborou com o projeto também tem formação em Biblioteconomia pela UFPA.
} 
Desenvolvendo a competência informacional: a experiência do curso de Biblioteconomia da UFPA com egressos do

sistema penal e familiares atendidos pela Fábrica Esperança
Rubens da Silva Ferreira; Maria Raimunda Sampaio; Maria de Nazaré dos Santos Corrêa; Armando Onofre da Silva Costa

acumulação como, também, o aumento do número de cientistas, de pesquisas, de publicações técnico-científicas e a introdução da informática e das telecomunicações no trabalho informacional (BORKO, 1968; MASUDA, 1996; CASTELLS, 1999; PINHEIRO; OLIVEIRA, 2012). Estas duas últimas, aliás, tornaram possível a comunicação e a interação remota com o advento das redes de informação, com destaque para a Internet, configurando a chamada sociedade da informação de Masuda (1996) e ou a sociedade informacional de Castells (1999) ${ }^{4}$, as quais podem ser entendidas como programas estatais delineados em torno da criação de infraestrutura e de políticas tecnoinformacionais de apoio aos governos, ao mercado e à sociedade. Logo, parte da literatura especializada trabalhada em sala de aula passa pela discussão e pela compreensão da informação, da sociedade da informação e dos muitos aspectos que se relacionam a esses conceitos, o que se faz, por exemplo, na disciplina Leitura e Competência Informacional.

Leitura e Competência Informacional (LCI) é uma disciplina nova no Projeto Político do Curso de Biblioteconomia da UFPA, sendo ofertada aos alunos desde 2009. Em nossa vivência docente, ela é trabalhada em dois momentos: (1) inicialmente nos conteúdos programáticos relacionados às questões históricas, conceituais e técnicas conexas ao ato de ler, tido como central nas bibliotecas, sobretudo nas de natureza escolar; e (2) nos conteúdos dedicados à competência informacional em sua dimensão conceitual e histórica. Encarado sob esta ótica, vê-se que o programa da disciplina pouco tem a ver com as questões práticas fundamentais no desenvolvimento das competências informacionais, o que acabou por inspirar a elaboração do projeto de extensão "Construindo a competência informacional através de estratégias de fortalecimento do uso educativo das Tecnologias de Informação e Comunicação". O objetivo da ação consistiu em colocar docentes e discentes em situações reais de interação com cidadãos no aprendizado do uso das TIC e, consequentemente, em sua capacidade de utilizá-las para acessar, organizar e intercambiar informações.

Com tradução não consensual do inglês infomation literacy, utilizado pela primeira vez em 1974, pelo advogado Paul Zurkowsky, que dirigiu por 20 anos a Information Industry Association, o termo competência informacional corresponde ao conjunto de conhecimentos, habilidades e atitudes aplicadas às práticas cotidianas dos indivíduos para a obtenção, a análise e o uso de informações no atendimento de suas atividades educacionais, laborais e de lazer, seja no plano individual ou coletivo (KUHLTHAU, 2002; CAMPELLO, 2003; DUDZIAK, 2003; MIRANDA, 2004). Dudziak (2003, p. 24), ao fazer uma revisão da literatura sobre o mesmo, mostra outras traduções possíveis na língua portuguesa, a saber, "alfabetização informacional, letramento, literacia [e] fluência informacional". Todavia, seja qual for a forma adotada no vernáculo, o certo que o conceito é alvo de controvérsias desde que se transformou em

\footnotetext{
${ }^{4}$ Adotaremos neste trabalho o termo sociedade da informação, dada a maior popularidade que ele possui em relação ao proposto por Castells.
} 
palavra de ordem do movimento de bibliotecários americanos iniciado nos anos de 1970, conhecido como information power (CAMPELLO, 2003), que reivindicava o reconhecimento pelo Estado do papel da classe bibliotecária na educação de jovens e de adultos nos EUA.

Assim, partindo da sala de aula, de um contexto de ensino/aprendizado problematizador sobre os conceitos de informação, sociedade da informação e competência informacional presentes na literatura especializada, a realização de um projeto de extensão impôs-se aos professores que ministram a disciplina LCI na FABIB. Nesta direção, enquanto três docentes ocuparam-se da articulação junto à Fábrica Esperança (Foto1) e do planejamento didático-pedagógico da iniciativa, um técnico-administrativo dedicou-se à documentação, bem como aos encaminhamentos gerencial e logístico do projeto ao longo de sua execução entre $1^{0}$ de agosto e 28 de dezembro de 2011. Além desses atores, 72 discentes de Biblioteconomia colocaram os conceitos trabalhados em sala de aula, seus conhecimentos e experiências no uso de TIC a serviço dos egressos do sistema penal e dos familiares atendidos pela Fábrica Esperança, precisamente aqueles relacionados ao editor de texto, planilhas eletrônicas e ao editor de apresentação do pacote gratuito Br.Office.Org, ${ }^{5}$ bem quanto ao uso de correio eletrônicos e da Internet, cada vez mais essenciais nas interações na sociedade da informação.

Foto 1 - Vista da Fábrica Esperança, projeto que funciona no bairro do Reduto, em Belém (PA), oferecendo oportunidades de cursos e de trabalho para egressos do sistema penal

Fonte: Rubens Ferreira (2011).

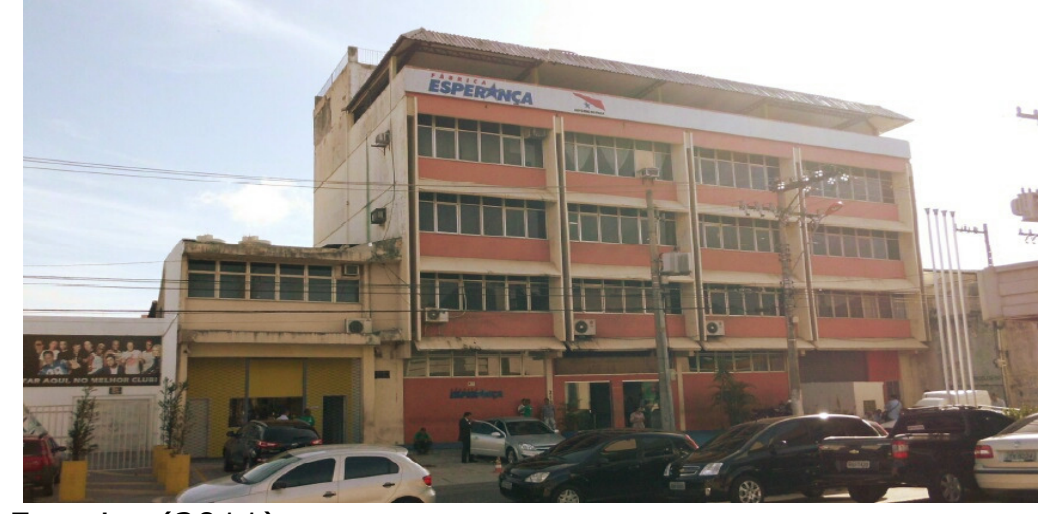

\section{Metodologia}

A ação extensionista foi realizada pela FABIB, em parceria com a Fábrica Esperança. Tal fábrica consiste em um projeto de ressocialização de egressos do sistema penal, atendendo, também, aos seus familiares, sendo mantido pela Associação Pólo Produtivo Pará, entidade sem fins lucrativos, conveniada à Superintendência do Sistema Penitenciário do

\footnotetext{
5 À época da atividade, esse pacote era utilizado no Laboratório de Informática da FABIB, o que possibilitou aos alunos adquirirem conhecimento sobre os programas que o compõem.
} 
Estado do Pará (SUSIPE) ${ }^{6}$. A iniciativa demandou o emprego da pesquisaação (THIOLLENT, 2007), em particular na identificação das demandas desse público junto à Fábrica Esperança, o que, após duas rodadas de reunião, apontou para a necessidade de reabertura do Infocentro do Projeto NavegaPará, mantido nesse espaço, mas que se encontrava desativado por falta de pessoal para atuar como facilitador nos cursos de inclusão digital.

Em termos operacionais, o projeto foi divido em dois momentos. A fase preparatória envolveu a realização de reuniões de planejamento entre a equipe do projeto e desta com a Diretoria de Reinserção Social da Fábrica Esperança, seguida por uma visita de reconhecimento e de inspeção ao Infocentro para a verificação das condições de funcionamento (Foto 2). Como este espaço encontrava-se fechado por longo período de tempo, houve a necessidade de manutenção e de atualização dos computadores, bem como o conserto do aparelho de ar-condicionado, o que se concluiu em um período de quase três meses após o contato inicial (Foto 3). Nesta fase, a equipe também se dedicou ao estudo do material didático fornecido pelo próprio NavegaPará e à inclusão de outros conteúdos relevantes à ação, tais como ética no uso da TIC, inclusão digital, a discussão do conceito de informação, sociedade da informação e de competência informacional, como elementos que se relacionam à vida dos indivíduos na atualidade.

Foto 2 - Vista interna do Infocentro, em visita de reconhecimento realizada no dia 25 de agosto de 2011 por docentes da FABIB, à direita, acompanhados por funcionários da Fábrica Esperança, à esquerda

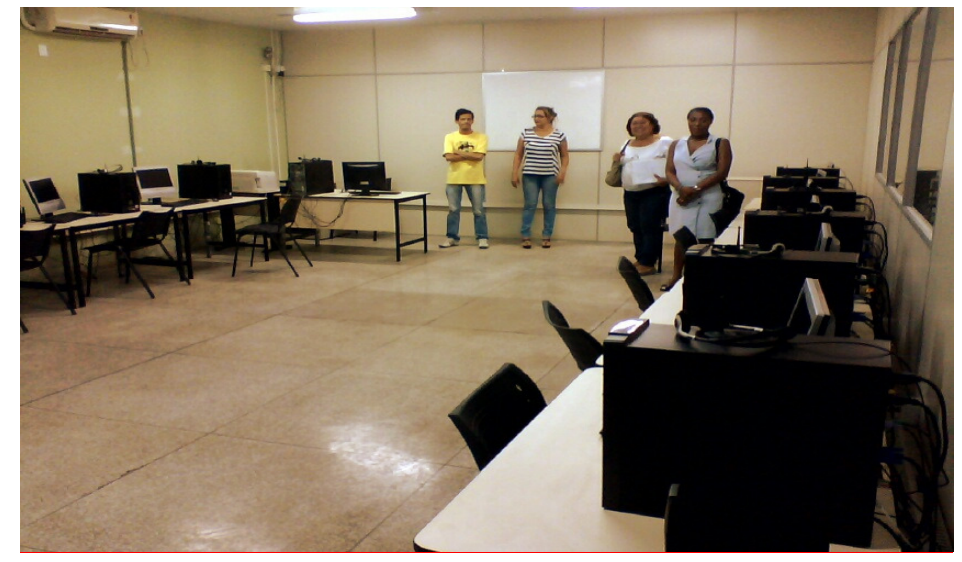

Fonte: Rubens Ferreira (2011).

Foto 3 - Registro fotográfico da reinauguração do Infocentro da Fábrica Esperança, realizada dia 7 de novembro de 2011. A ocasião contou com a presença de autoridades do governo do estado, funcionários, egressos, familiares e docentes envolvidos no projeto de extensão. Na imagem, o Infocentro pode ser visualizado à esquerda.

\footnotetext{
${ }^{6}$ A Fábrica Esperança mantém programas orientados para a educação e cultura, qualificação profissional, assistência social, saúde e qualidade de vida, acesso à justiça e garantia de emprego e renda.
} 


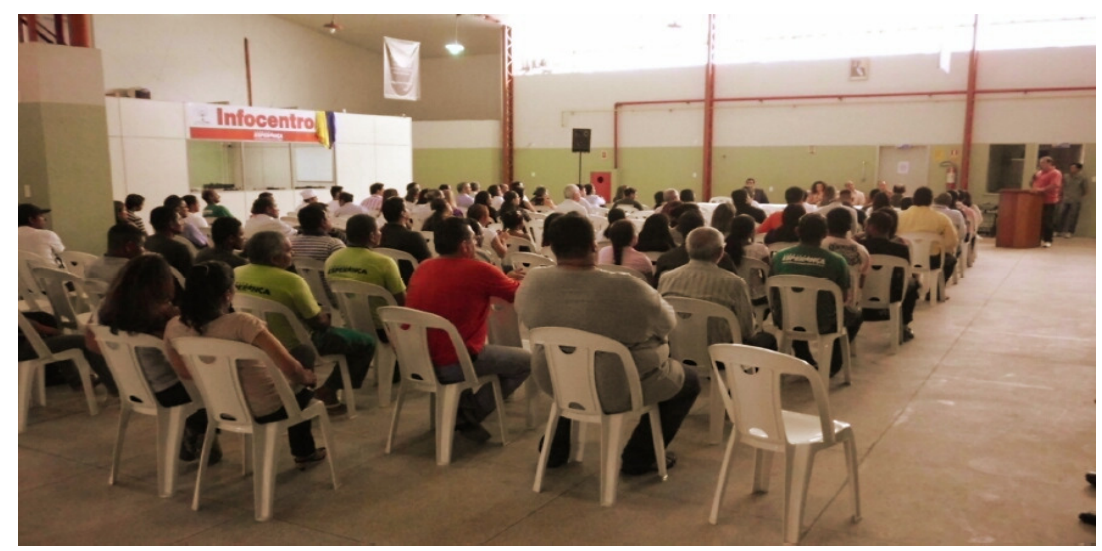

Fonte: Rubens Ferreira (2011).

O segundo momento, por sua vez, foi dedicado à ação de desenvolvimento das competências informacionais propriamente ditas, junto aos egressos e seus familiares. Assim, uma reunião entre docentes, discentes e membros da Diretoria de Reinserção Social da Fábrica Esperança foi fundamental para descontruir preconceitos sobre o públicoalvo da ação e orientar uma abordagem humana e cidadã aos mesmos. Posterior a esse diálogo, entre os meses de novembro e dezembro, docentes, discentes, egressos e familiares conviveram e interagiram no Infocentro da Fábrica Esperança em uma carga horária semanal de 20h, totalizando $160 \mathrm{~h}$ de atividades orientadas para o desenvolvimento das competências informacionais em duas turmas com 10 participantes cada: (1) a do período matutino, formada pelos egressos; e (2) a do período vespertino, formada pelos familiares ${ }^{7}$. Foi com base nessa metodologia que se pôde realizar o trabalho descrito a seguir.

\section{A Fábrica Esperança: o espaço da aplicação e da reflexão sobre o saber}

A vivência de docentes e de discentes no projeto levou à reflexão sobre a relação entre o conceito de competência informacional e o de inclusão, uma vez que ambos estão interligados ao uso das TIC, na sociedade da informação. Para Handdon (2000), é possível pensar em três formas de exclusão social em relação a essas tecnologias: (1) a autoexclusão, motivada pela rejeição do indivíduo às TIC; (2) a falta de acesso aos recursos informáticos por fatores de ordem econômica; e (3) a falta de habilidade no uso das TIC. Nessa perspectiva, ao se pensar em uma sociedade na qual as relações entre indivíduos, Estado e mercado são cada vez mais mediadas por redes como a Internet, o sentido de estar incluído envolve não apenas o acesso à tecnologia necessária a essa interação - o que já ocorre gratuitamente em espaços como os

\footnotetext{
${ }^{7}$ As atividades foram desenvolvidas no horário de $8 \mathrm{~h}$ às $12 \mathrm{~h}$ e das $14 \mathrm{~h}$ às $18 \mathrm{~h}$. Os discentes cursavam a disciplina tanto no período matutino quanto no período noturno, por isso se revezavam no projeto conforme a disponibilidade de tempo de cada um. Além de LCI, disciplinas ministradas pelas professoras colaboradoras também foram envolvidas na extensão, haja vista a relação que mantêm com a competência informacional. São elas: Prática em Mediação da Informação e Prática em Recuperação da Informação.
} 
Desenvolvendo a competência informacional: a experiência do curso de Biblioteconomia da UFPA com egressos do sistema penal e familiares atendidos pela Fábrica Esperança
Rubens da Silva Ferreira; Maria Raimunda Sampaio; Maria de Nazaré dos Santos Corrêa; Armando Onofre da Silva Costa

infocentros e telecentros espalhados pelo Brasil - como, também, a capacidade de saber utilizá-la. Logo, um primeiro passo a ser trabalhado, em direção ao desenvolvimento das competências informacionais, é capacitar homens, mulheres e crianças para o uso dos recursos informáticos, a fim de que possam localizar, processar, armazenar, recuperar e disseminar informações por si mesmos.

Partindo desse princípio discutido em sala de aula, o deslocamento para o mundo real mostrou aos docentes e aos discentes experiências diferenciadas do público-alvo do projeto no uso do computador e dos recursos que ele oferece. Entre os egressos do sistema penal, a oportunidade permitiu o primeiro contato com hardware e software, os quais eram desmitificados, à medida que trabalhávamos, explicando seu funcionamento e aplicações, com enfoque direcionado para as competências relacionadas à criação, ao registro, ao armazenamento e à recuperação da informação. Esse primeiro encontro do homem com a máquina por si só motivava os egressos para os encontros diários no Infocentro da Fábrica Esperança ${ }^{8}$. Utilizando um computador por pessoa, os conteúdos articulados pelos facilitadores estavam centrados inicialmente no ensino/aprendizado dos programas que formavam o pacote do Br.Office.Org, sendo que os aprendentes eram assistidos individualmente por monitores (Foto 4), preparados para dirimir as dúvidas e acompanhar o desenvolvimento de cada tarefa. Estas, por sua vez, correspondiam à elaboração de correspondências, relatórios de produção e de estoque, folhas de frequência, comunicados internos, planilhas de controle do orçamento doméstico e apresentações de slides.

Foto 4 - Na foto vê-se um dos egressos realizando atividade no computador, assistido por uma discente de Biblioteconomia, à direita

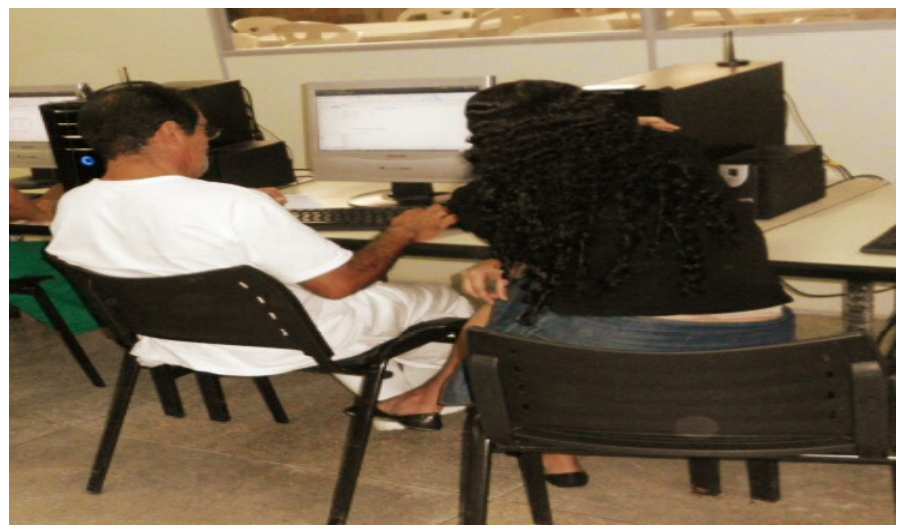

Fonte: Rubens Ferreira (2011).

Entre os familiares dos egressos, foram verificados níveis diferenciados de conhecimento sobre o uso dos computadores e suas

\footnotetext{
${ }^{8}$ Apesar do caráter social do projeto Fábrica Esperança, docentes e discentes sentiam o que era estar em um espaço estruturado para a disciplina e para a vigilância, o que se evidenciava pelo controle na entrada e pela própria arquitetura panóptica do infocentro, com suas paredes espelhadas e câmera interna instalada. Como diz Foucault (1984, p. 153): "O exercício da disciplina supõe um dispositivo que obrigue pelo jogo do olhar; um aparelho onde as técnicas que permitem ver induzam a efeitos de poder, e onde, em troca, os meios de coerção tornem claramente visíveis aqueles sobre quem se aplicam". Assim, docentes, discentes, egressos e familiares encontravam-se todos na condição de vigiados e subordinados à disciplina da Fábrica Esperança.
} 
Desenvolvendo a competência informacional: a experiência do curso de Biblioteconomia da UFPA com egressos do

sistema penal e familiares atendidos pela Fábrica Esperança
Rubens da Silva Ferreira; Maria Raimunda Sampaio; Maria de Nazaré dos Santos Corrêa; Armando Onofre da Silva Costa

aplicações. Enquanto alguns já haviam realizado cursos de computação com certificação, outros tinham contato com essa tecnologia a partir do acesso aos laboratórios de informática instalados nas escolas públicas em que estudavam. De todo modo, esse conhecimento prévio possuía limitações. A falta do uso contínuo do computador resultou em esquecimento entre aqueles que haviam obtido qualificação certificada. Por outro lado, os estudantes sabiam utilizar a rede social Orkut para postar mensagens e interagir com aqueles que faziam parte de seu grupo familiar ou de amigos, todavia, não sabiam realizar tarefas como criar documentos em editor de texto, trabalhar com planilhas de cálculo ou editor de apresentação, bem como formatá-los, salvá-los e organizá-los no computador para acesso e uso posterior. Assim, enquanto para os egressos a ação resultou em um conhecimento primeiro sobre o uso de hardware e de softwares, entre os familiares a experiência foi importante, no sentido de aprimorar e consolidar habilidades anteriormente adquiridas.

Com relação ao uso da Internet e dos recursos que ela oferece, as atividades concentraram-se no uso do correio eletrônico, da máquina de busca Google e no acesso a serviços como a obtenção da $2^{a}$ via de faturas de água e de luz. Em meio às possibilidades, a escolha por trabalhar tais conteúdos entre egressos e familiares se deu em função do entendimento que eles consistem em elementos básicos a serem conhecidos pelo cidadão na sociedade da informação.

Possuir um correio eletrônico no contexto da sociedade da informação corresponde à demarcação da existência simbólica do indivíduo no ciberespaço, pois todo e qualquer serviço utilizado na Grande Rede Mundial de Computadores passa pela posse uma conta de e-mail, seja para cadastrar-se em um banco de currículos, para reclamar junto a uma empresa, para fazer inscrição em concursos públicos, para solicitar serviços do Estado ou mesmo para participar de uma das diversas redes sociais que existem atualmente. O Google, por sua vez, é a ferramenta mais utilizada para a busca de informações na Internet (MORAIS; AMBRÓSIO, 2007), seja na forma de texto, de imagem ou de vídeo, oferecendo, ainda, aos usuários, uma variedade de outros serviços como ferramenta de tradução, recursos para a criação de blog, correio eletrônico e acesso a livros digitais. Quanto à geração de $2^{a}$ via de faturas de água e de luz, a preocupação de docentes e discentes consistiu em mostrar aos egressos e aos familiares que tais documentos podem ser obtidos pelo próprio consumir com o uso da Internet, portanto, sem que haja a necessidade do deslocamento físico até os prestadores desses serviços, reduzindo custos com transporte e evitando filas.

Assim, na fase em que se trabalhou a Internet e os recursos oferecidos por ela, o foco das atividades foi direcionado para as habilidades de intercambiamento - como o uso do correio eletrônico - e de busca de informações. Nesta etapa, não foram observados níveis diferenciados de habilidades dos egressos em relação aos seus familiares, pois mesmo tendo acesso a computadores e à Rede na escola ou nas 
Desenvolvendo a competência informacional: a experiência do curso de Biblioteconomia da UFPA com egressos do

sistema penal e familiares atendidos pela Fábrica Esperança
Rubens da Silva Ferreira; Maria Raimunda Sampaio; Maria de Nazaré dos Santos Corrêa; Armando Onofre da Silva Costa

chamadas lan houses, esse segundo grupo os utiliza mais para a comunicação remota em redes sociais ${ }^{9}$. Na prática de busca de informações, ambos os grupos eram livres ${ }^{10}$ para realizá-la de acordo com seus interesses temáticos e mediante a escolha de estratégias de pesquisa que se ajustavam ao seu nível de familiaridade com o computador. Páginas de museus, de bibliotecas, de receitas culinárias, de letras de músicas, de artistas, de poesias e de fotografias eram navegadas, observadas e, às vezes, salvas pelos aprendentes; uma experiência que para os egressos - com trajetórias de vidas marcadas pela pobreza e pela violência - comovia não só a eles mesmos como, também, a equipe do projeto.

Tem-se, nesse contexto, uma vivência extensionista, que se acredita ter resultado em ganhos mútuos para todos os atores envolvidos. Em uma dimensão prática, por meio do projeto, a Fábrica Esperança certificou a qualificação de 10 egressos e de 10 familiares em cursos sobre os softwares do pacote Br.Office.org (Br.Write, Br.Calc e Br.Apresentação) e Internet, com duração total de $160 \mathrm{~h}$, nas quais se procurou desenvolver, também, as competências informacionais do público atendido. No âmbito da graduação, cinco discentes integralizaram 300h e outros 67 obtiveram 40h para crédito na atividade curricular "Extensão em Biblioteconomia". Três docentes e um técnico-administrativo adquiriram experiência nessa modalidade de atividade e dedicaram-se, também, à produção científica, com publicação de artigo e apresentação de trabalho na 64a. Reunião da Sociedade Brasileira para o Progresso da Ciência, realizada São Luís (MA), em 2012. Desse modo, espera-se que, de alguma forma, o projeto tenha contribuído para uma formação mais cidadã dos(as) futuros(as) bibliotecários (as), despertando-os(as) para o papel social que têm a desempenhar na sociedade da informação.

\section{Considerações finais}

A combinação entre ensino e extensão viabiliza um processo ensinoaprendizagem contextualizador. Isto significa dizer que a transposição das teorias e dos conceitos trabalhados em sala de aula para fora da universidade permite a construção de um conhecimento mais crítico, precipuamente ao articular e confrontar o conteúdo da literatura técnicocientífica com as adversidades e os contrastes que só a realidade pode oferecer aos olhos de docentes e de discentes. Ademais, a flexibilidade e as múltiplas interações sociais que sustentam a experiência extensionista podem revelar habilidades e competências às vezes não percebidas na

\footnotetext{
${ }^{9}$ Durante as atividades, era frequente observar indivíduos do grupo dos familiares acessando seus perfis no Orkut para ler e postar mensagens. Essa prática, aliás, não era inibida pelos docentes nem pelos discentes, uma vez que o mais importante na estada no Infocentro da Fábrica Esperança era poderem manipular o computador e a Internet o máximo de tempo possível.

${ }^{10}$ Docentes e discentes orientavam os egressos e seus familiares quanto à necessidade do uso ético desses recursos, uma vez que as práticas ilegais no ciberespaço não estão isentas das sanções normativas previstas no mundo real, a exemplo daquelas que se aplicam aos casos de plágio, calúnia e difamação, invasão da privacidade, pedofilia e outras.
} 
Desenvolvendo a competência informacional: a experiência do curso de Biblioteconomia da UFPA com egressos do

sistema penal e familiares atendidos pela Fábrica Esperança
Rubens da Silva Ferreira; Maria Raimunda Sampaio; Maria de Nazaré dos Santos Corrêa; Armando Onofre da Silva Costa

rotina e no ambiente limitador da sala de aula, onde a única relação possível é a do tipo professor/aluno. Neste sentido, foi possível observar o empenho de alguns discentes nas atividades realizadas junto aos egressos e aos familiares atendidos pela Fábrica Esperança, o que pode ser um indicador da vocação para o exercício da docência na Biblioteconomia num futuro próximo ${ }^{11}$. E, por fim, ao lado da pesquisa, a extensão precisa ser mais ampliada no curso de Biblioteconomia da UFPA, sobretudo como estratégia de fortalecimento e de investimento na qualidade no ensino de graduação.

\section{Agradecimentos}

À Faculdade de Biblioteconomia e à Direção da Fábrica Esperança pelo acolhimento ao projeto. Aos egressos e aos familiares pela vivência humana rica em aprendizado. Aos alunos e alunas de Biblioteconomia, que voluntariamente doaram o tempo livre ao projeto.

\section{Referências}

BELKING, N. J.; ROBERTSON, S. E. Information science and the phenomenon of information. Journal of the American Society for Information Science, p. 197-203, July/Aug. 1976.

BORKO, H. Information science: what is it? American Documentation, v. 19, n. 1, p. 3-5, Jan. 1968.

CAMPELLO, B. O movimento da competência informacional: uma perspectiva para o letramento informacional. Ciência da Informação, Brasília, v. 32, n. 3, p. 28-37, set./dez. 2003.

CASTELLS, M. Fim de milênio. 3. ed. São Paulo: Paz e Terra, 1999. (A era da informação: economia, sociedade e cultura; 3).

COCCO, G. Indicadores de inovação e capitalismo cognitivo. In: BASES

conceituais em pesquisa, desenvolvimento e inovação. Brasília, DF: Centro de

Gestão e Estudos Estratégicos, 2010. p. 3-68. Disponível em: $<$ http://www.cgee.org.br/atividades/redirect.php?idProduto=6403 > . Acesso em: 13 jan. 2013.

DUZZIAK, E. A. Information literacy: princípios, filosofia e prática. Ciência da Informação, Brasília, v. 32, n. 1, p. 23-35, jan./abr. 2003.

FOUCAULT, M. Vigiar e punir: história da violência nas prisões. 3. ed. Petrópolis: Vozes, 1984.

HADDON, L. Social exclusion and information and communication technologies: lessons from studies of single parents and the young

\footnotetext{
${ }^{11}$ Inclusive egressos, familiares e funcionários da Fábrica Esperança faziam comentários dessa natureza aos docentes, demonstrando admiração e preferência por um ou por outro discente que trabalhava como facilitador nas atividades desenvolvidas no Infocentro.
} 
Desenvolvendo a competência informacional: a experiência do curso de Biblioteconomia da UFPA com egressos do

sistema penal e familiares atendidos pela Fábrica Esperança
Rubens da Silva Ferreira; Maria Raimunda Sampaio; Maria de Nazaré dos Santos Corrêa; Armando Onofre da Silva Costa

elderly. New media \& society, v. 2, n. 4, p. 387-406, 2000. Disponível em:

< http://rcirib.ir/articles/pdfs/cd1/Ingenta_Sage_Articles_on_194_225_11_89/Ingenta764.pdf >. Acesso em: 22 fev. 2013.

KUHLTHAU, C. Como usar a biblioteca na escola: um programa de atividades para o ensino fundamental. Belo Horizonte: Autêntica, 2002. (Formação humana na escola).

MASUDA, Y. A sociedade da informação como sociedade pós-industrial. Rio de Janeiro: IPEA; Brasília, DF: PNUD, 1996.

MIRANDA, S. V. Identificando competências informacionais. Ciência da Informação, Brasília, v. 33, n. 2, p. 112-122, maio/ago. 2004. Disponível em: <http://revista.ibict.br/ciinf/index.php/ciinf/article/view/83/76 >. Acesso em: 22 mar. 2013.

MORAIS, E. A.; AMBRÓSIO, A. P. L. Ferramentas de busca na Internet. Relatório Técnico: Universidade Federal de Goiás; Instituto de Informática, 2007. Disponível em: $<$ http://www.inf.ufg.br/sites/default/files/uploads/relatorios-tecnicos/RT-INF_002-07.pdf > . Acesso em: 22 mar.. 2013.

PINHEIRO, L. V. R.; OLIVEIRA, E. P. de. Prefácio. In: PINHEIRO, L. V. R.; OLIVEIRA, E. P. de. Múltiplas facetas da comunicação e divulgação científicas: transformações em cinco séculos. Brasília, DF: IBICT, 2012. p. 10-16. Disponível em: <http://ibict.phlnet.com.br/anexos/multiplasfacetas.pdf $>$. Acesso em: 18 mar. 2013.

THIOLLENT, M. Metodologia da pesquisa-ação. 15. ed. São Paulo: Cortez, 2007. 